\title{
Cervical Cancer cT0 TNM Finding v8
}

National Cancer Institute

\section{Source}

National Cancer Institute. Cervical Cancer CTO TNM Finding v8. NCI Thesaurus. Code C139689.

Cervical cancer with no evidence of primary tumor. (from AJCC 8th Ed.) 